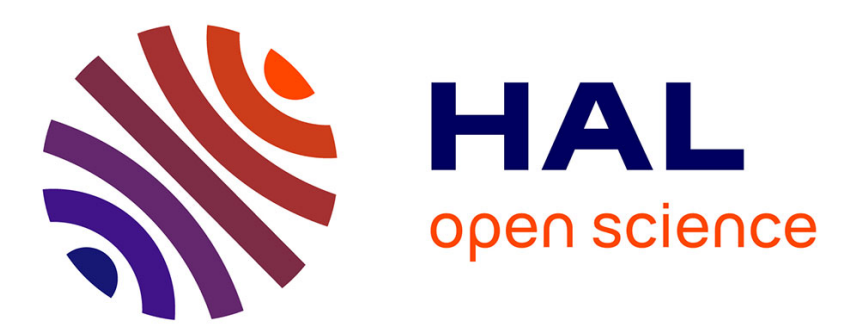

\title{
Modular architecture of the microfactories for automatic micro-assembly.
}

\author{
Dominique Gendreau, Michaël Gauthier, David Hériban, Philippe Lutz
}

\section{To cite this version:}

Dominique Gendreau, Michaël Gauthier, David Hériban, Philippe Lutz. Modular architecture of the microfactories for automatic micro-assembly.. Journal of Robotics and Computer Integrated Manufacturing., 2010, 26 (4), pp.354-360. 10.1016/j.rcim.2009.11.013 . hal-00503826

\section{HAL Id: hal-00503826 \\ https://hal.science/hal-00503826}

Submitted on 19 Jul 2010

HAL is a multi-disciplinary open access archive for the deposit and dissemination of scientific research documents, whether they are published or not. The documents may come from teaching and research institutions in France or abroad, or from public or private research centers.
L'archive ouverte pluridisciplinaire HAL, est destinée au dépôt et à la diffusion de documents scientifiques de niveau recherche, publiés ou non, émanant des établissements d'enseignement et de recherche français ou étrangers, des laboratoires publics ou privés. 


\title{
MODULAR ARCHITECTURE OF THE MICROFACTORIES FOR AUTOMATIC MICRO-ASSEMBLY
}

\author{
Dominique Gendreau, Michaël Gauthier, David Hériban, Philippe Lutz \\ FEMTO-ST Institute - AS2M Department - UFC-ENSMM-UTBM - CNRS UMR 6174 \\ 24 rue Alain Savary - 25000 BESANCON - France \\ dominique.gendreau@univ-fcomte.fr ; michael.gauthier@femto-st.fr ; david.heriban@femto-st.fr ; philippe.lutz@femto-st.fr
}

\begin{abstract}
The construction of a new generation of MEMS which includes micro-assembly steps in the current microfabrication process is a big challenge. It is necessary to develop new production means named micromanufacturing systems in order to perform these new assembly steps. The classical approach called "top-down" which consists in a functional analysis and a definition of the tasks sequences is insufficient for micromanufacturing systems. Indeed, the technical and physical constraints of the microworld (e.g. the adhesion phenomenon) must be taken into account in order to design reliable micromanufacturing systems. A new method of designing micromanufacturing systems is presented in this paper. Our approach combines the general "top-down" approach with a "bottom-up" approach which takes into account technical constraints. The method enables to build a modular architecture for micromanufacturing systems. In order to obtain this modular architecture, we have devised an original identification technique of modules and an association technique of modules. This work has been used to design the controller of an experimental robotic micro-assembly station.
\end{abstract}

Keywords: micromanufacturing systems, flexibility, productivity, modularity, MEMS assembly

\section{Introduction}

Currently, the development of new functionalities of the Micro Electronic and Mechanical Systems (MEMS) which are applied in the medical field, communications, multimedia, aerospace equipment or car components requires hybrid technologies [1]. The current techniques of production are not adapted to the variety, the complexity, the volume of production and the specificity of assembly steps.

In fact, several steps need to be followed to assemble new micromechatronic products for two main reasons:

- the monolithic fabrication of these products is no longer sufficient to obtain 3D MEMS microstructures;

- they have to integrate hybrid technologies, such as optical, mechanical and electronic components; each of them requires their own means of production.

Packaging techniques or microbonding like chip on board, tape automated bonding and flip chip bonding exist in the field of electronics and MEMS. However, these methods which were developed to join two wafers together cannot be used for complex and 3D products. Self-assembly is usually used in the field of chemistry or chemical biology, and for mechanical microcomponents [2], but it is insufficient for complex products mainly because it is dedicated to a specific product with a small number of components.

Let us call the assembly of several microcomponents, where the typical size of each component is several $100 \mu \mathrm{m}$ but does not exceed 1mm, a "microproduct". A "micromanufacturing system" is a production system which is able to achieve microproducts.

We focus on manufacturing microproducts which are organised in small or medium batches. In fact, we do not consider oneoff production which is rather the subject of manual or assisted operations. In addition, we do not treat mass production, which is ensured by some specific production systems.

In this paper, we will show that modularity, the concept successfully tested in the manufacturing system, has a strategic place in the microworld. In the first part, we will present our current work and previous evolutions in micromanufacturing systems. Following that, we will present the specificities of the microworld and the requirements in micro-assembly techniques, and we will show the interest of a modular structure at this scale. Then, we will propose a method based on the concept of modularity which is adapted to the particularities of the microworld and the specific constraints of the environment. Finally, we will focus on the application of our method; it has been carried out on an experimental micro-assembly station. Experiments show the viability and the efficiency of the modular control architecture on the micromanufacturing system.

\section{Current Work}

The complete production of micromechatronic systems has led to the development of new micromanufacturing systems able to manufacture microcomponents in batches. The present challenge is to associate the possibilities of microrobotics and the 
constraints of production systems. At the moment, for industrialisation, it is necessary to take into account parameters like flexibility and productivity, according to time and cost criteria.

The first desktop microfactory was developed at the MEL/AIST/MITI in Japan. This system consisted of several micromachines for production [3]. The goal of this prototype was to prove the feasibility of such a system for the manufacture and assembly of a small bearing. This microfactory does not integrate the constraints of production.

In addition Japanese companies such as Olympus Optical or Seiko Instruments Inc. have developed prototypes; an assembly system for micro-optical products and a teleoperation system for minuscule components for the former, a processing unit (electro-chemical etching and depositing of materials by applying voltage between material and a probe) and assembling unit (several modules made of micromachine devices) for the latter.

Evolution over the last twenty years shows a growth in the degree of automation (figure 1). In 1990, systems required the permanent assistance of an experienced operator to move and to assemble microcomponents. These situations led to long execution delays and an important failure rate. Consequently microproducts remained rare and expensive. Progress in microtechniques, combined with computer performances, which are useful for vision systems and for control equipment, has permitted the development of human interfaces. The challenge is now to develop micromanufacturing systems which are more powerful in response to the increasing demand of products.

Three progress axes has been identified: the first considers the growth of the level of technology which enables a more thorough miniaturization and better performances; the second is the automation degree in order to achieve productions which can be easily batched; the third deals with the capacity to rapidly change the production. In addition, some perirobotic functions can be taken into account, like the connection to a feeding system to increase the degree of autonomy and

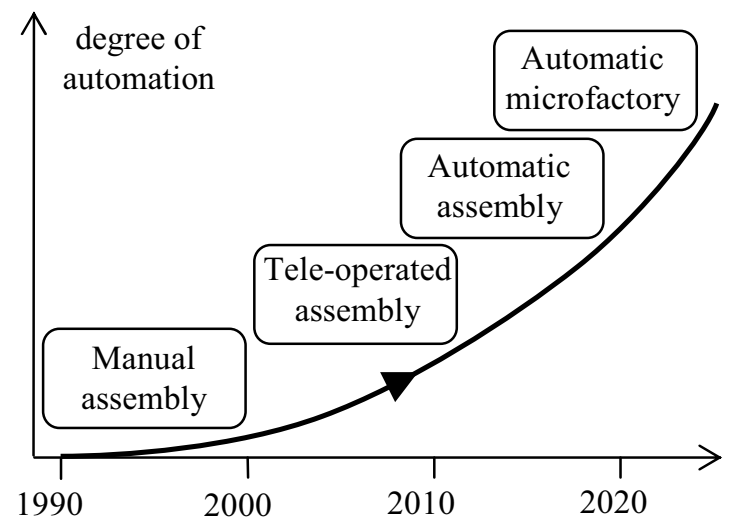
thus automation.

\section{Micromanufacturing Systems and Modularity Analysis}

We have identified four essential differences which characterize micromanufacturing systems compared to human scale systems: the indeterministic process carried out by the system, the difficulty to enable the intervention of an operator in the microworld, the characteristics of the components of the production platform and finally the lack of know-how in the design of production systems.

\subsection{The Influence of Stochastic Behaviour on Micromanufacturing Processes in the Microworld}

It clearly appears that assembly functions (positioning, velocity control, force sensing, joining, visioning, etc) are more complex in micromanipulation than in manipulation on a human scale [4]. With all these constraints, it is useful to have more flexibility in micromanufacturing systems in order to easily adapt the configuration of production.

Micromanufacturing systems cannot be based on the rules which are well-known in manufacturing systems on a millimetre scale because of a lesser knowledge of the phenomena in micro-assembly tasks. In fact, indeterministic situations occur too frequently. Although basic models of microforces exist [5], it is currently impossible to predict the behaviour of the process. The predominant forces in the microworld are very sensitive to all environmental parameters (humidity, temperature, ionic concentration in liquid, etc.) and the influence of external parameters has not been precisely described yet. Most of the time it is thus necessary to carry out several tests before finding a correct strategy for reliable production. Micromanufacturing systems must be able to auto-adapt easily and quickly to a new configuration, thanks to a modular architecture.

\subsection{The operator's level of intervention}

Considering safety procedures, an operator can work on a system which is tailored on a human scale. Micromanufacturing systems are inaccessible for people, because human sensing and manipulating capacities are not adapted. Visual and tactile limits combined with precision (several hundreds of micrometers of amplitudes) make it impossible for a direct manual intervention in microsystems. Perception and interventions in the microworld therefore require human interfaces.

A structured organisation built around several modules enables to adapt systems easily during human interventions or maintenance actions. The exchange of interfaces, like a mouse or a joystick, or a simple camera or a stereovision system has to 
be done as "plug and play" without the difficulties of connection or configuration. This modularity approach must be applied on hardware but also on software.

\subsection{Production Organisation}

On a human scale, a manufacturing system is composed of large machinery weighing several tons. A micromanufacturing system is composed of several small production cells weighing several kilograms, which enables them to be removed easily. Thus, the management of a production system could be done in a new way, where the position of production cells is reoptimized every time production changes. It is thus important that each cell should be easily adaptable, reconfigurable (simple connections, sure configurations and fast calibrations). Consequently, a modular structure is interesting to be able to change the hardware configuration of production systems. It allows us to achieve a first level of modularity.

\subsection{Modular Design of Micromanufacturing Systems}

The design of a classical manufacturing system involves equipments produced by manufacturers. Each manufacturing process requires expertise work which allows the study and the implementation of appropriate and efficient pieces of equipment. On a micrometer scale, microsensors and micro-actuators are constantly being developed and the market changes rapidly. Their integration in a small production cell is thus not easy. The standardization of these pieces of equipment is a major challenge for the design of progressive micromanufacturing systems.

To increase performances in terms of adaptability of micro-assembly systems, we propose to go further by introducing modularity inside the cells. In this condition, we can progressively integrate new sensors or actuators, according to recent technological evolution.

In the past there have been several concepts trying to improve the capacity to organise production; the robotic and automation contributions, then the computer integrated manufacturing (CIM) concepts followed by concurrent engineering. We are offering a new concept of modularity as it has been shown that modularity could bring positive elements compared to a classic production system [6]. The problem is different in the case of micromanufacturing systems because the splitting them into modules largely depends on technological constraints and their use. This particular point is examined in this paper. Modularity can cover various aspects: the global organisation structure, the control aspect which integrates data structure, the physical interfaces with mechanical connections, the distribution of energies, or the physical network; we have concentrated our research on the first two points.

\section{Method to Build this Modular Architecture}

In this section we are going to present a method which allows the design of the modular architecture of a micromanufacturing system.

\subsection{Current Approaches of Modular Architecture}

On a human scale, several approaches have been developed to build a modular structure. The precursors of all modular approaches are reconfigurable systems [7-9]. Later, Lohse et al. [10] combined the function, the structure and the behavioural aspect to allow rapid configuration of assembly systems. Literature clearly shows that a modular approach makes the reconfiguration of systems easier. For example, a component based approach enables the control system to be reconfigurated easily [11]. Some other approaches deal with the adaptation of the production system to the product [12]. All these approaches are complementary [13], but they are limited on a human scale system, and do not integrate the specificities of the microworld [14] [15].

A few researchers in the microworld field have worked on control architecture for micromanufacturing systems. A centralized control system based on a JAVA framework was developed, enabling a microfactory to increase its capacity very easily [16]. Modular aspects were used, but the system is not dynamic enough for the execution of multiple tasks. Likewise, the propositions of Gaugel et al. [17] answer an optimal flexibility of the material configuration but are not adapted to a dynamic control organisation.

\subsection{A Dual Approach for the Design of Micromanufacturing Systems}

The objective of our approach is to provide a modular architecture to completely define the cells which compose the production platform. Several methods of designing a manufacturing system, which integrate various points of views, like the functional, the information and the behavioural view of the system exist [18]. For our application, the functional model is completed with SADT ${ }^{\mathrm{TM}}$ [19], and the behaviour axis can be developed with the help of several tools: state models [20], Petrinets [21] and/or Grafcet [22]. These tools allow a top-down approach that is suitable for the majority of manufacturing systems 
to be characterised. This method is generally sufficient for current manufacturing systems because, except in the case of a failure, the behaviour of the actuators is similar to the description and the synchronization of the tasks in the cells.

However, it is still insufficient to obtain the detailed physical description of each production cell in micromanufacturing systems.

In fact, this first method must be supplemented by a bottom-up approach (figure 2) that is guided by technological constraints. Indeed, the structure and boundaries in the cell are highly dependent on the technology of materials used. An analysis of the technological components of each cell is used to represent the basic elements.

This dual approach enables the cells and the pieces of the cell equipment to be defined by characterization of hardware and associated control, including the environment of the component [23].

\subsection{Top-down analysis}

First, a SADT analysis gives a global structure which defines all the functions of the system (e.g. "prepare the station" or "assemble two microparts").

The starting point of the method consists in making a functional analysis of the system with SADT; this model also permits a global structure of the system to be built. The SADT analysis allows the decomposition of functions from a global function level to a level of detail which always guarantees a purely functional description and for which the dynamic aspect does not appear. This level of description of elementary functions can be realized by different technical solutions (figure 3). Thus modularity is preserved.

For each solution which allows to satisfy an elementary function, a technique, a means and a sequence which describe how the function is carried out are thereby associated.

A "catch of a component" function can be carried out by a technique either involving mechanical tightening, air depression, temporary joining or electrostatic load, according to a control sequence.

Each solution consists in a sequence described by Grafcet which can be directly implemented in a robot.

The tasks executed by the functional modules are composed of logical sequences of actions (figure 4) which represent sequential behaviour (e.g. "locate the position" then "approach the gripper" then "grasp the micropart"...).

\subsection{Bottom-up analysis}

Then, the elementary modules which integrate technology constraints are described: micro-actuators (Ai), specific control laws $(\mathrm{Lj})$ end-effectors (Ek), microsensors ( $\mathrm{Sl})$.

Each positioning stage consists of an elementary actuator, which transforms a control signal into a mechanical energy. It characterizes micro-actuator modules Ai (figure 5).

Micro-actuator technologies like piezoelectric, thermal or

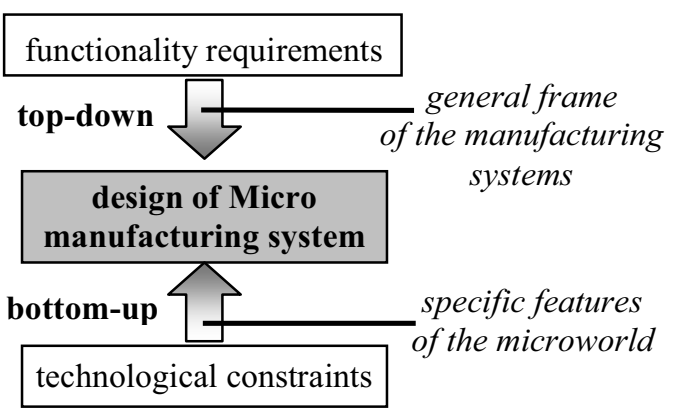

Figure 2: proposed design approach of micromanufacturing systems

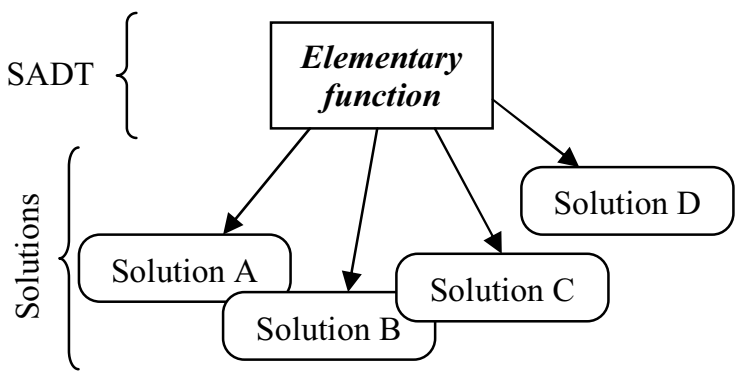

Figure 3: links between the SADT model and different technical solutions

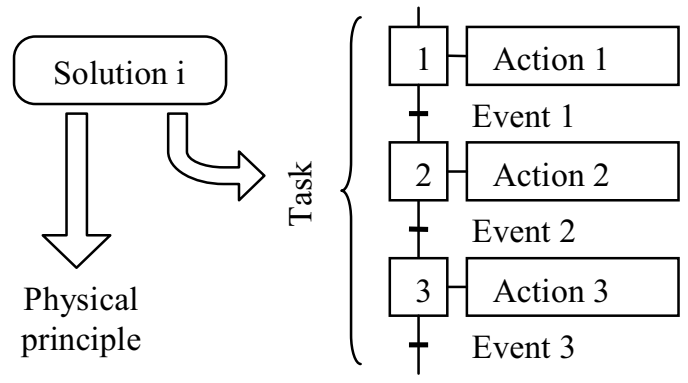

Figure 4: description of a solution by a sequence of actions

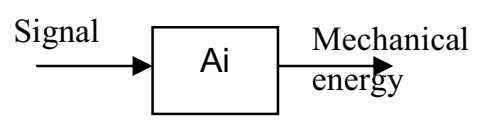

Figure 5: micro-actuator module representation 
electrostatic technologies have nonlinear behaviour. It is therefore necessary to develop several control laws (Lj) [24]. The L2 module can be used to control different micro-actuators (A1 or A2) which have the same technology (figure 6).

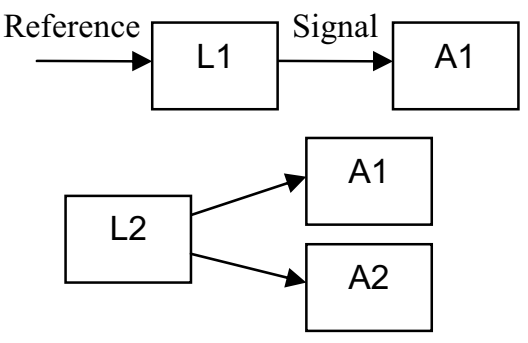

Figure 6: representation of the law of control module

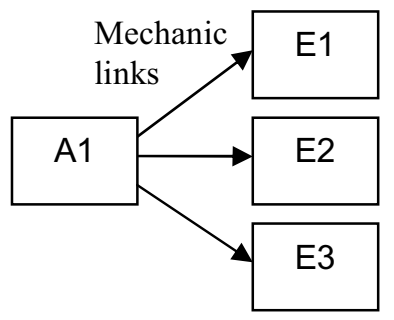

Figure 7: end-effectors module representation

In a gripper, there are two different types of elements: the actuators which are controlled elements and end-effectors which are passive elements. In micromanipulation, it is often necessary to adapt the form, the thickness or the roughness of end-effectors. A parameter setting (like a coefficient) is enough to take into account the geometrical and dimensional characteristics of endeffectors, without having an effect on the control law. These elements are named Ek (figure 7).

Finally, major automated systems react to their environment via sensors. In the context of micromanipulation, position encoders and force sensors are most usually used, by techniques of vision, or piezoresistive systems. They can adapt to several entities of control order and are represented by the S1 modules (figure 8).

One of the particularities of our approach is the ability to modelize components which may be "multifunctional". For example, a piezoelectric beam may be used as a sensor (direct piezoelectric effect) or actuator (inverse piezoelectric effect), depending on the assembly scenario. This method, usually called "self-sensing", is currently used in micromanufacturing systems to reduce the size of components. The same piezoelectric beam can be considered as two elementary modules: a sensor and an actuator (figure 9). Our modularity approach has taken into account this specificity of technological microcomponents.

Each action described in the top-down analysis can thus be realized with a constituent module obtained by an adaptive combination of several elementary modules.

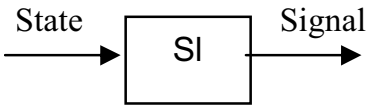

Figure 8: sensors module representation

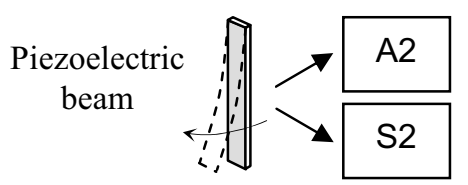

Figure 9: the two possibilities of modular modelling of a piezoelectric beam

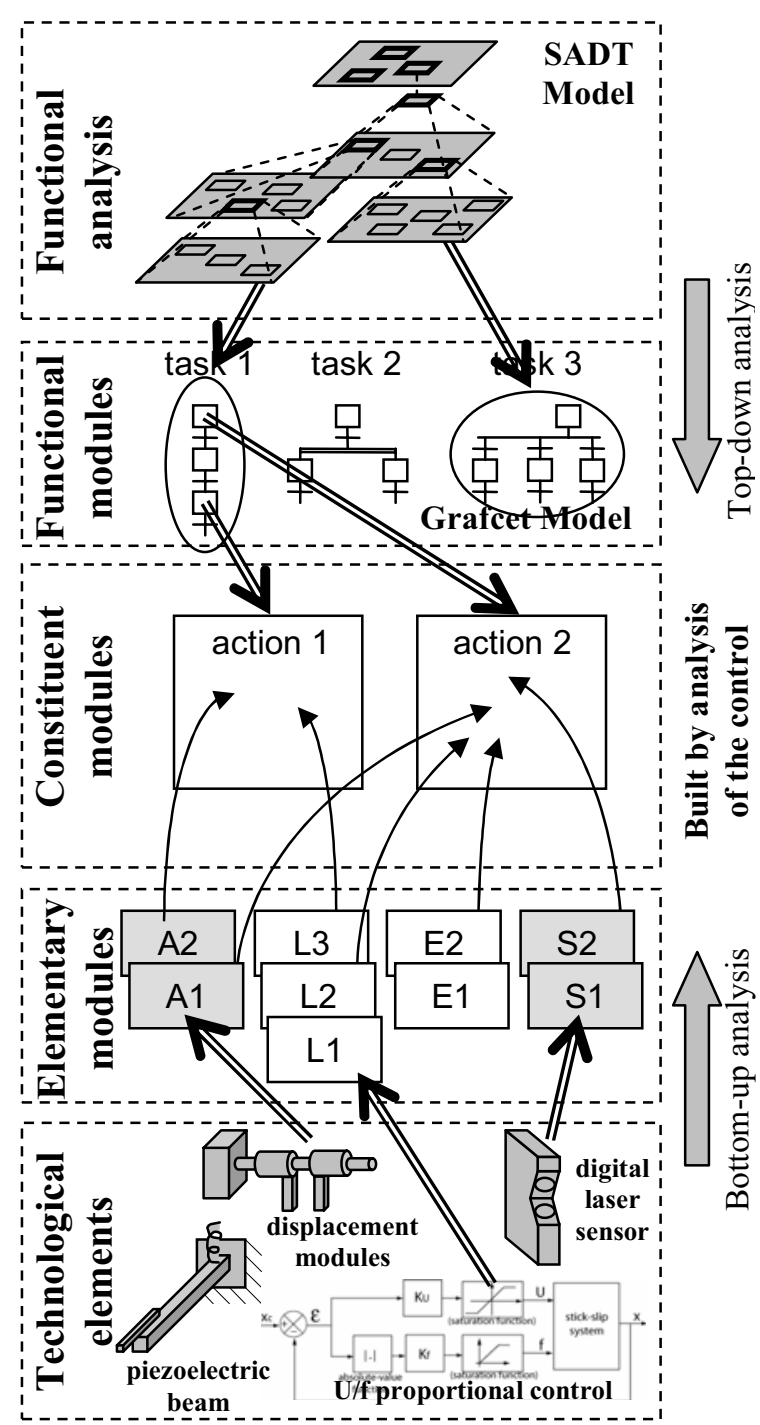

Figure 10: the design technique of constituent modules 


\subsection{Link Between both Approaches}

In our method (figure 10), multiple levels of constituent modules can be used: a constituent module is composed of elementary modules, but can also include other constituent modules.

For example, a movement can be obtained by a single actuator, with a control law based on a model of the actuator (e.g. the control of a piezoelectric beam, including a hysteresis correction).

In this case the constituent module is composed of a control law and an actuator. Moreover, this system could need a vision sensor to achieve a visual servoing while preserving hysteresis correction. This other module is thus composed of a constituent module, a control law and a camera. For example, a classical control loop is represented in figure 11 .

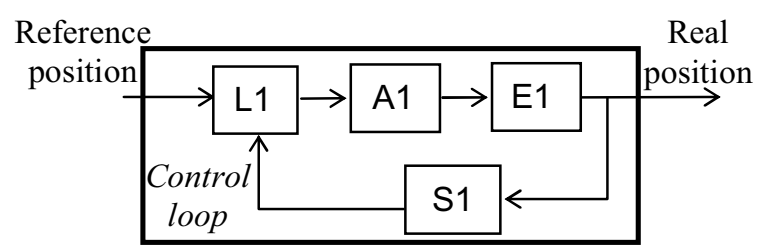

Figure 11: constituent module result for a classical control loop

\section{Application on a Robotic Micro-assembly Station}

This modularity concept was applied on the design of a micromanufacturing system developed in the PRONOMIA research project [5]. The robotic station is able to perform the tele-operated micro-assembly of silicon objects whose general size is as small as $40 \mu \mathrm{m}$. Automatic pick and place operations of these objects are also available [25]. The station is presented in figure 12 .

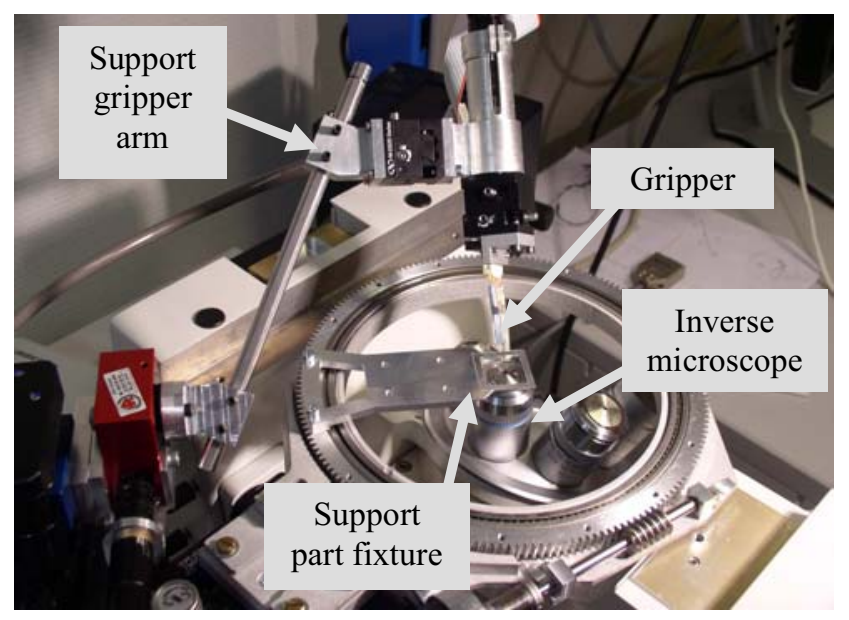

Figure 12: robotic microassembly station
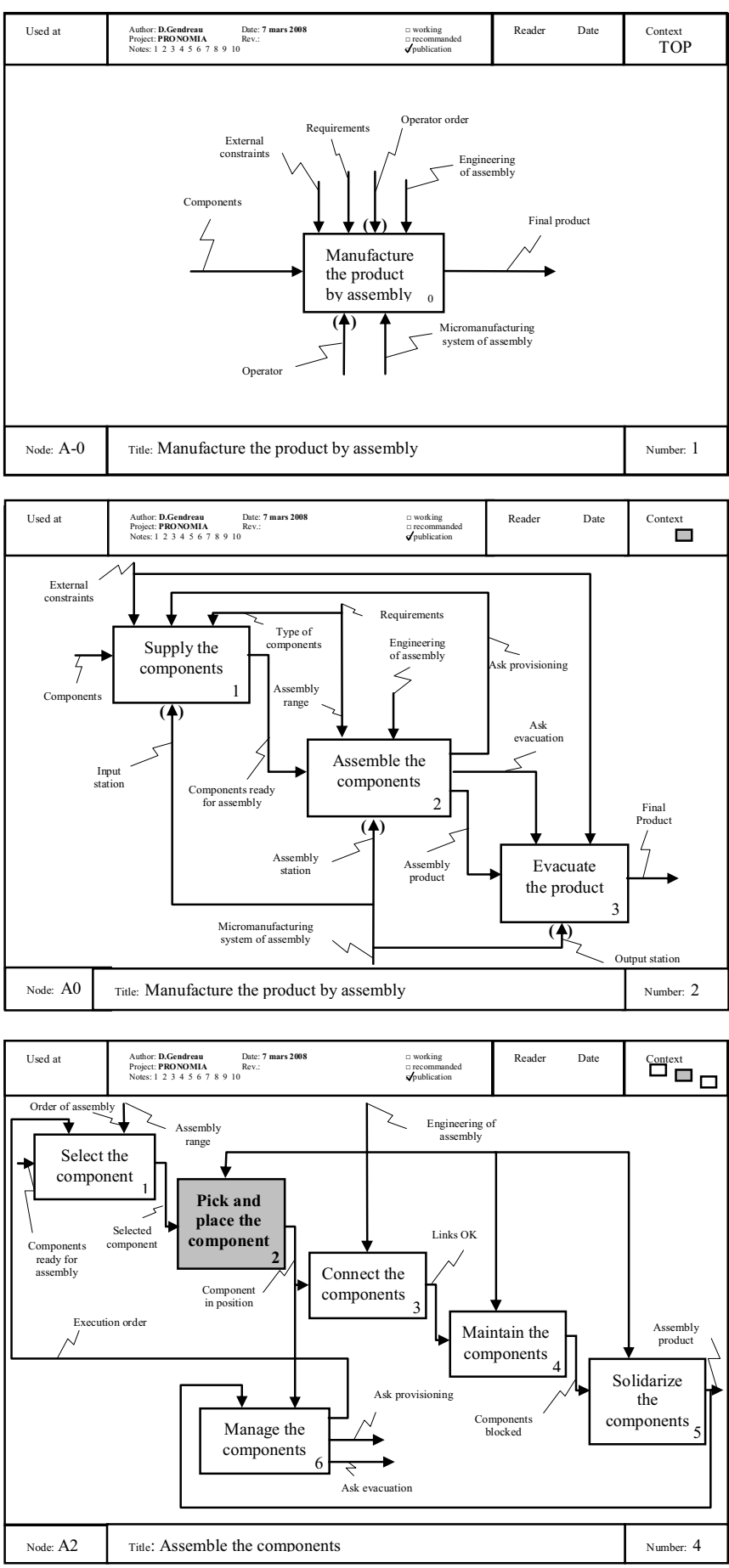

Figure 13: SADT model (A-0, A0, A2 diagram)

The first phase of the method consists in the functional analysis carried out with the SADT analysis. Figure 13 shows a part of this functional analysis (only the diagrams A-0, A0 and $\mathrm{A} 2$ are represented). In the A2 node, the level of decomposition is sufficient to identify six elementary functions necessary to "assemble the components". 
Box number 2 represents the elementary "pick and place the component" function. This function cannot usefully be broken up into sub-functions any further, as it is the subject of a sequence of executions.

In order to illustrate the modular control architecture, let us use the example of a pick and place task, in which several modes of displacement can be obtained, according to required precision, required time or geometric configuration. The sequence of manipulation can be divided into several actions, as is described in figure 14. In the following figure, we consider three cases of movement.

We offer to study the different displacement cases. To achieve this, we need to define several modules. The elementary A1 module represents a translation stage able to induce movement in the station. The kinematical model is integrated into a L1 law of control.

For step 1 in the Grafcet model in figure 14, the first action requires a displacement which is not precise, but must be done quickly. An open-loop control represented as a constituent module (Figure 15a) is used.

In the second action referenced in step 2 in figure 14, a microcomponent has to be grasped; therefore it is necessary to have a very high precision (some micrometers). This control strategy needs a S1 sensor to measure the real position of the gripper. In our case, an inverse microscope is used. The visual control is represented in figure $15 \mathrm{~b}$, as a new constituent module.

The third action (step 4, figure 14) requires a micropart to be moved to a new position with the gripper, without it falling onto the floor and without crushing it. Thus, it is necessary to control the pressure force during the whole trajectory, with a S2 force sensor and a specific L3 control law (figure 15c). The forcecontrolled gripper could be considered as a A'1 constituent module.

The three actions use the same elementary modules during the assembly operation in different configurations. In this application, the execution of the functional module described in figure 14 was possible thanks to one actuator, three control laws and two sensors.

The hardware configuration of the system is not modified during the production process and each functional module will use the same elementary modules. A new production scenario can be easily designed and built in the controller using our modular approach. In fact, the ability to easily define new scenarios enables the assembly strategy to be rapidly changed when perturbations appear in the microworld. Moreover the modification of a hardware component (e.g. modification of an actuator) can be easily done by replacing the new elementary module in the controller.

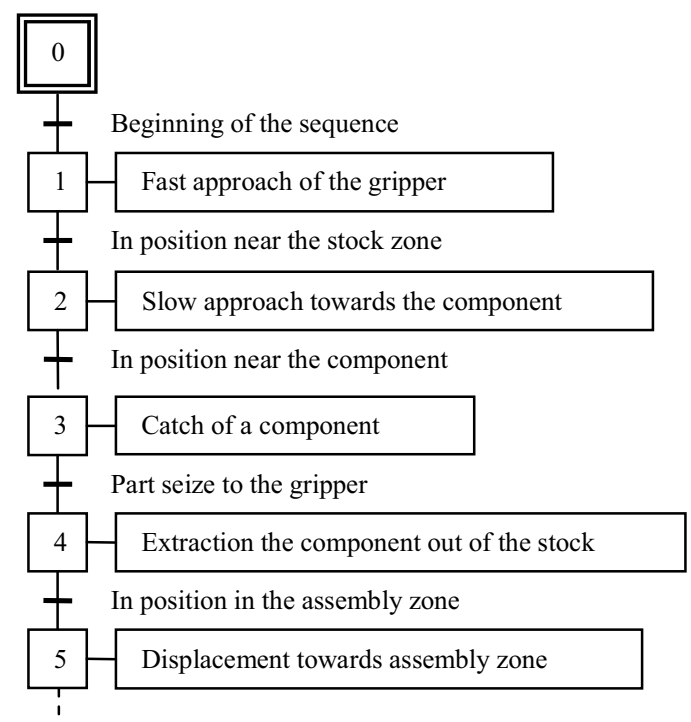

Figure 14: grafcet of an pick and place sequence

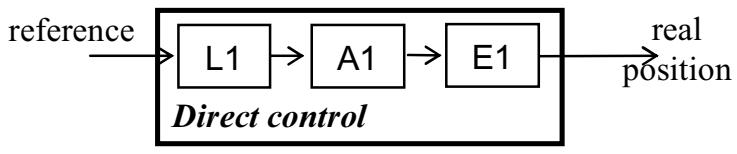

(a) open-loop control of rough movements

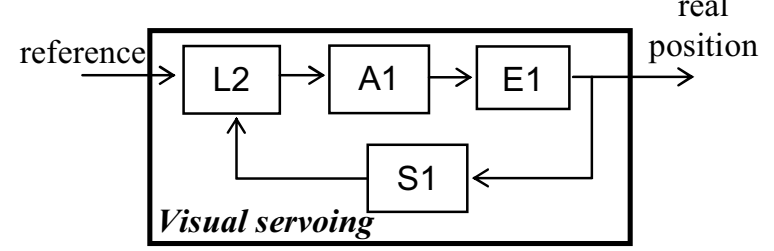

(b) close-loop control of fine movements

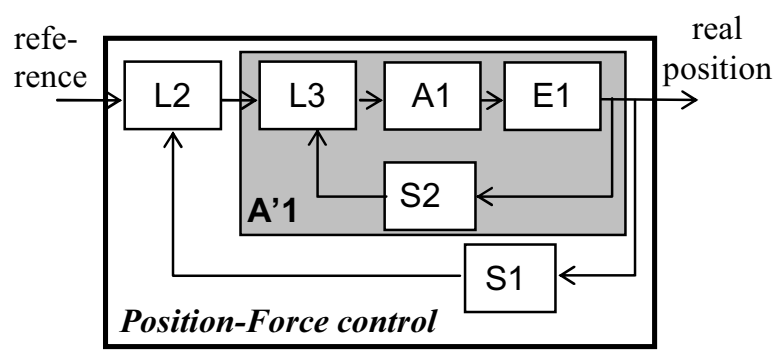

(c) hybrid force-position control

Figure 15: several control configurations using modular decomposition

\section{Conclusion}

This work deals with a new way of designing the control architecture of micromanufacturing systems using a modular approach. The study of components like actuators and sensors on the microscale enables the microworld to progress constantly. The architecture of a micromanufacturing system must be able to easily replace components by using new technological solutions. Moreover the behaviour of micro-objects is highly affected by the environment and is currently not predictable. Consequently, the assembly scenarios are required to be able to change rapidly in order to adapt to the modifications of the behaviour of micro-objects during a production process. Major microscale specificities on production systems can be solved by 
using high modular control architecture. Our method is based on two complementary approaches coming from functional analysis and technological constraints. Our method has been used to design the control architecture of an experimental microassembly platform.

\section{Acknowledgement}

This work is supported by the PRONOMIA research project-ANR no. 05-BLAN-0325-01

\section{References}

[1] Mounier E., De Charentenay Y., Eloy J.-C. New applications for MOEMS, In: Proceedings of SPIE, MOEMS display, imaging, and miniaturized microsystems IV, ISSN 0277-786X, vol. 6114, p. 611405.1-611405.5, San Jose, California, USA, January 25-26, 2006.

[2] Fang J, Wang F, Böhringer KF. Self-Assembly of PZT actuators for micropumps with high process repeatability. Journal of Microelectromechanical Systems 2006;15(4):871-8.

[3] Ashida K., Mishima N. et al., Development of desktop machining microfactory, Japan-USA Flexible Automation Conference, Ann Arbor, Michigan, July 23-26, 2000.

[4] Popa DO, Stephanou HE. Micro and mesoscale robotic assembly. Journal of Manufacturing Processes 2004;6(1):52-71.

[5] Gauthier M., Hériban D., Gendreau D., Régnier S., Chaillet N. Micro-factory for submerged assembly: interests and architectures, In: Proceedings of the 5th International Workshop on Microfactories, IWMF'06, Besancon, France, October 25$27,2006$.

[6] Rogers G.G., Bottaci L., Modular production systems: a New manufacturing paradigm, International Journal of Intelligent Manufacturing, Chapman \& Hall, London, England, 1997;8(2):147-156.

[7] Koren Y, Heisel U, Jovane F, Moriwaki T, Pritchow G, Van Brussel H, Ulsoy AG. Reconfigurable manufacturing systems. CIRP Annals 1999;48(2):527-40.

[8] Mehrabi MG, Ulsoy AG, Koren Y. Reconfigurable manufacturing system and their enabling technologies. International Journal of Manufacturing Technology and Management 2000;1(1):113-30.

[9] Yigit AS, Ulsoy AG, Allahverdi A. Optimizing modular production in a reconfigurable manufacturing system. Journal of Intelligent Manufacturing 2002;13(4).

[10] Lohse N., Ratchev S., Chrisp A., Function-behaviour-structure model for modular assembly equipment, Micro-factory for Precision Assembly Applications, International Precision Assembly Seminar, February 11-13, 2004.

[11] Berruet P., Lallican J.-L., Rossi A., Philippe J.-L., A component based approach for the design of FMS control and supervision, IEEE SMC, the Big Island, Hawaii, USA, October 10-12, 2005.

[12] Gouyon D, Pétin J-F, Morel G. A Product-driven reconfigurable control for shop floor systems. Studies in Informatics and Control, with Emphasis on Useful Applications of Advanced Technology 2007;16(1).

[13] Dashchenko A, Anatoli I, editors. Reconfigurable Manufacturing Systems and Transformable Factories. Heidelberg, ISBN: 3-540-29391-4.

[14] Nelson BJ, Breguet J-M. Microrobotic and micro-assembly III. Proceedings of SPIE 2001;4568.

[15] Gauthier M, Regnier S, Rougeot P, Chaillet N. Forces analysis for micromanipulation in dry and liquid medium. Journal of Micromechatronics 2006;3(3-4):389-413.

[16] Codourey A., Honegger M., A centralized control system for microfactories, Third International Workshop on Microfactories, IWMF'02, Minneapolis, Minnesota, September 16-18, 2002.

[17] Gaugel T., Bengel M., Malthan D., Schliesser J., Kegeler J., Munz G., Miniaturized reconfigurable micro-assembly system, Microfactory for Precision Assembly Applications, International Precision Assembly Seminar, Bad Hofgasfeln, Austria, February 11-13, 2004.

[18] Yourdon editor. Modern structured analysis and systems specification, Englewood Cliffs, New Jersey: Yourdon Press; 1989.

[19] Marca DA, McGowan CL. In: SADT: structured Analysis and Design Technique. McGraw-Hill; 1987.

[20] Harel D. First-Order Dynamic Logic. Lecture notes in computer science, New York: Springer-Verlag; $1979 ; 68$.

[21] Petri, C.A., Concepts of net theory, In: Proceedings of Symposium and Summer School on Mathematical Foundations of Computer Science, High Tatras, September 3-8, Mathematical Institute of the Slovak Academy of Sciences, p. 137-146, 1973.

[22] International Electrotechnical Commission, Grafcet specification language for sequential function charts, International Standard, IEC 60848, $2^{\text {nd }}$ ed. 94 p., February 2002.

[23] Rakotondrabe M, Haddab Y, Lutz P. Development, modelling and control of micro/nano positioning 2 DoF stick-slip device. IEEE/ ASME Transactions on Mechatronics, IEEE/ASME TMech 2009;14(6):733-45.

[24] Rakotondrabe M, Haddab Y, Lutz P. Voltage/frequency proportional control of stick-slip micropositioning systems. IEEE Transactions on Control Systems Technology 2008;16-6:1316-22.

[25] Hériban D., Gauthier M., Robotic Micro-assembly of microparts using a Piezogripper, In: proceedings of IEEE/RSJ International Conference on Intelligent Robots and Systems (IROS), Nice, France, September 22-26, 2008. 